\title{
COLONIALIDADE E VIOLÊNCIA NA AMÉRICA LATINA: uma leitura do romance Amuleto, de Roberto Bolaño
}

\author{
COLONIALITY AND VIOLENCE IN LATIN AMERICA: a reading of the \\ novel Amuleto, by Roberto Bolaño
}

\section{COLONIALIDAD Y VIOLENCIA EN AMÉRICA LATINA: una lectura de la novela Amuleto, de Roberto Bolaño}

Fábio da Silva Sousa ${ }^{1}$

\begin{abstract}
RESUMO: Este artigo tem como objetivo realizar uma aproximação do conceito de Colonialidade e suas vertentes, de Anibal Quijano, com o romance Amuleto, de Roberto Bolaño. A Colonialidade, enquanto leitura epistêmica da dominação capitalista proposto por Quijano, também pode ser expandido para o campo cultural e, aqui em especial, com a literatura. Amuleto narra à história de Auxilio Lacouture, poetisa uruguaia, que estava radicada no México na década de 1960. Nesse período, o país mexicano foi escolhido como sede dos XIX Jogos Olímpicos, ao mesmo tempo em que uma juventude questionadora saiu às ruas para denunciar a corrupção governamental. O ápice desse embate aconteceu em 1968, quando a Universidad Autónoma do México (UNAM) foi invadida pelo exército e, uma multidão de jovens foi covardemente atacada
\end{abstract}

\footnotetext{
${ }^{1}$ Fábio da Silva Sousa é Doutor em História e Sociedade pela Faculdade de Ciências e Letras, UNESP - Universidade Estadual Paulista, docente e coordenador do curso de História da Universidade Federal de Mato Grosso do Sul - UFMS/CPNA e docente permanente do Programa de Pós-graduação stricto sensu interdisciplinar em Estudos Culturais da Universidade Federal de Mato Grosso do Sul - UFMS/CPAq/PPGCult. Líder do Grupo de Pesquisa do CNPQ: "Laboratório Interdisciplinar de Estudos Culturais (LindeCult)" e autor do livro "Sonhos revolucionários e pesadelos ardentes: El Machete, A Classe Operária e a luta da imprensa comunista mexicana e brasileira (1920-1930)" publicado em 2020 pela Paco Editorial. O presente trabalho foi realizado com apoio da Universidade Federal de Mato Grosso do Sul - UFMS/MEC Brasil. fabio.sousa@ufms.br.
} 
por snipers, a serviço do governo, na Praça de Três Culturas de Tlatelolco. Esses acontecimentos violentos do México estão no romance de Bolaño, que apresenta as suas reflexões dessa América Latina violentada a partir das memórias de Lacouture que, na ficção, escondeu-se no banheiro da UNAM no momento de sua invasão pelas tropas do exército. A partir dessa provocação, será defendido aqui que a obra Amuleto, tem enredos que dialogam e cruzam com o conceito de Colonialidade de Quijano, no qual a violência e a dominação tornaram-se uma ferida aberta em toda a América Latina.

Palavras-chave: Massacre da Praça de Tlatelolco; Literatura latino-americana; Roberto Bolaño.

ABSTRACT: This article aims to approximate the concept of Coloniality and its aspects, by Anibal Quijano, with the novel Amuleto, by Roberto Bolaño. Coloniality, as an epistemic reading of the capitalist domination proposed by Quijano, can also be expanded to the cultural field and, here in particular, with literature. Amulet tells the story of Auxilio Lacouture, a Uruguayan poet, who was based in Mexico in the 1960s. During this period, the Mexican country was chosen to host the 19th Olympic Games, at the same time that a questioning youth took to the streets to denounce the government corruption. The climax of this clash came in 1968, when the Autonomous University of Mexico (UNAM) was invaded by the army and a crowd of young people was cowardly attacked by snipers, a government service, in Tlatelolco's Three Cultures Square. These violent events in Mexico are in Bolaño's novel, which presents as his reflections on this violated Latin America based on the memories of Lacouture, who, in fiction, hid in the bathroom of UNAM at the time of his invasion by army troops. From this provocation, it will be defended here that the work Amuleto, has plots that dialogue and intersect with the concept of Quijano's Coloniality, in which violence and domination became an open wound throughout Latin America.

Keywords: Massacre of Tlatelolco Square; Latin American Literature; Roberto Bolaño.

RESUMEN: Este artículo pretende aproximar el concepto de colonialidad y sus vertientes, de Anibal Quijano, con la novela Amuleto, de Roberto Bolaño. La colonialidad, como lectura epistémica de la dominación capitalista propuesta por Quijano, también puede extenderse al campo cultural y, aquí en particular, a la literatura. Amuleto cuenta la historia de Auxilio Lacouture, una poeta uruguaya radicada en México en la década de 1960. Durante este período, el país mexicano fue elegido para albergar los XIX Juegos Olímpicos, al mismo tiempo que una juventud cuestionadora salió a las calles para denunciar la corrupción gubernamental. El clímax de este enfrentamiento llegó en 1968, cuando la Universidad Autónoma de México (UNAM) fue invadida por el ejército y una multitud de jóvenes fue cobardemente atacada por francotiradores, al servicio del gobierno, en la Plaza de las Tres Culturas de Tlatelolco. Estos hechos violentos en México están en la novela de Bolaño, que presenta sus reflexiones sobre esta América Latina violada a partir de la memoria de Lacouture, quien, en la ficción, se escondió en el baño de la UNAM en el momento de su invasión por tropas del ejército. De esta provocación, se defenderá aquí que la obra

Cadernos de estudos culturais, Campo Grande, MS, v. 2, p. 63-76, jul./dez. 2020. 
Amuleto, tiene tramas que dialogan y se cruzan con el concepto de Colonialidad de Quijano, en el que la violencia y la dominación se han convertido en una herida abierta en toda América Latina.

Palabras llave: Masacre de la plaza de Tlatelolco, Literatura latinoamericana, Roberto Bolaño.

\section{INTRODUÇÃO: primeiras palavras.}

Em 1968 o México foi palco de sonhos e pesadelos. Ao mesmo tempo em que o governo do presidente Gustavo Díaz Ordaz Bolaños (1964-1970) preparava o país para sediar o XIX Jogos Olímpicos, estudantes, em sintonia com a contestação social que ecoava em outras partes do mundo, protestaram contra a corrupção e a violência patrocinadas pelos mandatários mexicanos. Como um vulcão prestes a entrar em erupção, o ápice desse descontentamento aconteceu em 02 de outubro de 1968, quando milhares de estudantes foram às ruas em repúdio a invasão efetuada pelo exército na Universidad Nacional Autónoma de México (UNAM). Essa juventude concentrou-se na Plaza de las Tres Culturas e, forças policias e militares, acampadas nos prédios ao redor, abriram fogo contra os estudantes desarmados e patrocinaram um verdadeiro massacre. Esse acontecimento ficou marcado na história como o Massacre de Tlatelolco. Mais de 50 anos depois, os números das vitimas ainda é uma incógnita. De acordo com os dados oficiais, morreram dezenas de pessoas, enquanto outras fontes afirmam que foram centenas. Sem embargo, o XIX Jogos Olímpicos, o primeiro na América Latina, continuou e a impunidade deste ato perdurou por décadas na sociedade mexicana. De acordo com Alberto del Castillo Troncoso, as análises do Massacre de Tlatelolco produziu duas memórias carregadas de sentimentos e críticas sociais:

En investigaciones recientes se ha señalado la existencia de dos memorias sobre el movimiento estudiantil de 1968: la correspondiente a la "denuncia", surgida a fines de los años sesenta, como consecuencia de la impunidad de la matanza del 2 de octubre, y la del "elogio", nacida en la década de los setenta, como parte del proceso de recuperación política y cultural del movimiento, que poco a poco fue leído como pieza clave de la transformación del sistema político mexicano (CASTILLO TRONCOSO, 2012, p. 14).

Entre a denúncia e o elogio apresentado por Castillo Troncoso, atualmente a sociedade mexicana está lidando culturalmente com esse trauma, com a publicação de livros, produção de filmes, documentários, entre outros produtos 
culturais que trouxeram ao lume essa contradição violenta do México do final de 1960.

O estopim que explodiu a revolta estudantil mexicana, a invasão militar na UNAM, ocorreu em agosto de 1968. Essa intervenção ordenada pelo presidente Díaz Ordaz teve como objetivo sufocar a intensa crítica estudantil e evitar que esses protestos chegassem às camadas mais populares da sociedade mexicana. $\mathrm{O}$ maio de 1968 francês ainda ecoava pelo mundo e era um exemplo que deveria ser evitado. Como resultado dessas tensões, Javier Barros Sierra, reitor da UNAM à época, esteve à frente de uma manifestação de mais de 80 mil pessoas contra a intervenção governamental que colocou em xeque a autonomia universitária e renunciou ao cargo em 23 de setembro. O presidente Díaz Ordaz afirmou que essas manifestações eram atos de subversivos contra a nação mexicana e o senado autorizou o uso das forças armadas para manter a "segurança e a ordem interna e externa do país" (SMITH, 2015, p. 152-153), cujos resultados traumáticos já foram apresentados no início deste artigo.

O campo literário foi importante na produção de escritos sobre esse período turbulento da sociedade mexicana e o presente artigo tratará de uma obra em especial, Amuleto, do escritor argentino Roberto Bolaño. Publicado em 1999, Amuleto narra a saga de Auxilio Lacouture, uma poetisa uruguaia, radicada no México, que vivenciava a noite boemia da antiga capital dos astecas e tornou-se uma personagem célebre entre os poetas, ensaístas e outros artistas mexicanos. $\mathrm{Na}$ narrativa de Bolaño, Lacouture estava no banheiro feminino da UNAM no exato momento da intervenção militar. A poetisa escondeu-se dos militares e o romance descreve esses momentos tensos de exclusão, em que Lacouture recordou-se da sua vida, dos diversos artistas que teve algum tipo de contato e da violência que se tornou um imperativo na América Latina. Amuleto já foi objeto de algumas investigações acadêmicas. Curiosamente, duas dissertações, uma de 2012 da Universidade Estadual de Campinas (UNICAMP) e outra de 2015, da Universidade de Brasília (UNB) apresentaram, a partir de perspectivas díspares, uma análise entre Amuleto com outras romances de Roberto Bolaño, Estrela Distante e Noturno do Chile. A primeira, de autoria de Carmen Cecilia Rodríguez Almonacid, investigou as diversas memórias discursivas e a crítica social que Bolaño utilizou na escrita de ambas as obras, com destaque ao Massacre de Tlatelolco e do governo ditatorial chileno do Gen. Augusto Pinochet (1973-1990). Já o segundo estudo, de autoria de Clara Bomfim dos Santos, também colocou lado a lado Amuleto e Noturno do Chile e analisou a representação literária da 
violência, a memória, a cultura, entre outros elementos dessas duas narrativas. Um elemento interessante apresentada por Santos foi uma breve discussão sobre o conceito de Colonialidade presente em Amuleto. Ao destacar a discussão de Colonialidade do Saber de Walter Mignolo e o balbucio teórico de Hugo Achugar, a autoria afirmou que:

A partir das reflexões de Mignolo e Achugar, podemos pensar Amuleto no contexto das teorias pós-coloniais latino-americanas. Auxilio narra os fatos desde uma margem social e literária que implica mobilidade, nomadismo, resistência ao poder. $\mathrm{O}$ relato dessa narradora, que se encontra numa situação extrema, rompe com a temporalidade a apresenta uma série de anacronismos, projetando sua voz desde sua reclusão forçada durante a invasão militar da UNAM, espaço esse que se resume ao banheiro feminino da universidade (SANTOS, 2015, p. 60).

Esse esboço analítico de Santos é pertinente, instigante e promissor. Contudo, a autora não apresentou com densidade os pontos de ligação da Colonialidade com a trama de Amuleto. A perspectiva colonial do relato em primeira pessoa de Auxilio Lacouture apresenta outros elementos do que os apresentados por Santos e, na discussão que será apresentada no presente artigo, irei além da análise de que o relato da personagem literária mergulha em "uma série de anacronismos". Essa mobilidade temporal, como será apresentado a seguir, discorre não apenas sobre os eventos traumáticos do México no ano de 1968, como também do Chile de 1973 e da América Latina como um laboratório de violência e de disputa geopolítica. A partir dessa provocação, pretende-se aqui realizar uma aproximação do romance com o conceito de Colonialidade, formulado por Aníbal Quijano, no qual será tecida uma teia que aproximará os lugares latino-americanos do final da década de 1960 e início de 1970, com o hibridismo violento da Guerra-Fria (1945-1991). Auxilio Lacouture e outra figura literária, Arturo Belano - que será destacado adiante - são os principais personagens dessa ópera melancólica.

\section{COLONIALIDADE E LITERATURA: Amuleto e os espaços de violência latino-americanos}

O pensador peruano Aníbal Quijano inovou ao provocar uma leitura dos movimentos históricos e sociais da América Latina, a partir do conceito de Colonialidade. Em linhas gerais, a Colonialidade seria fruto do Colonialismo iniciado a mais de cinco séculos, quando o europeu cruzou o Atlântico. Para Quijano, a Colonialidade é um conceito operante no qual o Capitalismo mantém- 
se alimentado a partir da "imposição de uma classificação racial/étnica da população do mundo [...]" (QUIJANO, 2010, p. 84), enquanto o Colonialismo é um acontecimento histórico com espaço e tempo determinados. Além do extermínio promovido pelo universo europeu em cima dos povos originários, que tiveram os seus corpos mutilados e a sua cosmologia religiosa violentamente atacada, o poder epistêmico colonial também invadiu as Américas, com o Iluminismo e o Eurocentrismo. Esses conceitos advindos da Modernidade provocou uma classificação sociocultural, no qual, os habitantes da Europa seriam o ponto máximo da civilização em comparação com outros povos.

Desde o século XVIII, sobretudo com o Iluminismo, no eurocentrismo foi-se afirmando a mitológica ideia de que a Europa era preexistente a esse padrão de poder, que já era antes um centro mundial de capitalismo que colonizou o resto do mundo, elaborando por sua conta, a partir do seio da modernidade e da racionalidade. E que nessa qualidade, a Europa e os europeus eram o momento e o nível mais avançados no caminho linear, unidirecional e contínuo da espécie. Consolidou-se assim, juntamente com essa ideia, outro dos núcleos principais da colonialidade/modernidade eurocêntrica: uma concepção de humanidade segundo a qual a população do mundo se diferenciava em inferiores e superiores, irracionais e racionais, primitivos e civilizados, tradicionais e modernos (QUIJANO, 2010, p.86).

Por meio do contato dessas civilizações, a européia com os grupos étnicos originários das Américas, o Capitalismo configurou-se em escala mundial, a partir do processo de exploração colonial e da categorização racial advinda da Modernidade (QUIJANO, 2005, p. 228). Essa definição favorável ao universo europeu, no qual o branqueamento tornou-se um padrão a ser seguido, foi peremptório no processo de conquista das terras do novo mundo, em que os indígenas, negros, mestiços, entre outros, gradativamente seriam apagados pelo motor progressista da história. Esse processo foi intenso até as primeiras décadas do Século XX e, como demonstrado por George Reid Andrews (2007), algumas nações latino-americanas a utilizaram como política de Estado. Outros autores expandiram esse conceito de Quijano, como Walter Mignolo com a Colonialidade do Ser e María Lugones com a Colonialidade de Gênero. Para os objetivos do presente artigo, me deterei na concepção de Quijano.

Apresentado esse quadro teórico, seria possível pensarmos a Colonialidade do Poder de Aníbal Quijano em outros campos culturais e, aqui em especial, na Literatura? Ouso afirmar que sim. Antes de apresentar os argumentos dessa assertiva, em primeiro lugar, vamos nos deter no objeto do presente artigo, o romance Amuleto, de Roberto Bolaño. 
Publicado em 1999, e como já salientado em outras partes aqui, Amuleto apresenta aos leitores as desventuras de Auxilio Lacouture. Uruguai, hippie, poetisa e boemia, Lacouture vivenciou o mundo cultural e noturno do universo underground mexicano no final da década de 1960 e início de 1970, a tal ponto que se colocava como "[...] a amiga de todos os mexicanos. Poderia dizer: sou a mãe da poesia mexicana, mas acho melhor não dizer" (BOLAÑO, 2008, p. 09). A linguagem do romance está em primeira pessoa e, são a partir das palavras, das memórias, desejos, entre outros sentimentos de Lacouture, que entramos na leitura de Roberto Bolaño deste México de sonhos e pesadelos. Imediatamente, no primeiro paragrafo, os leitores são apresentados à temática que será desenvolvida ao longo da trama: "Esta será uma história de terror. Será uma história policial, uma narrativa de série negra e de terror. Mas não parecerá. Não parecerá porque sou eu que conto. Sou eu que falo e por isso não parecerá. Mas no fundo é a história de um crime atroz" (BOLAÑO, 2008, p. 09). Terror e crime são duas palavras que na obra literária apresentam-se como conceitos operantes e vivos e evidenciam-se na descrição de Lacouture em suas lembranças sobre a invasão da UNAM:

[...] Que vontade de chorar! Estou chorando? Vi tudo e, ao mesmo tempo, não vi nada. Entendem o que quero dizer? Sou a mãe de todos os poetas e não permiti (ou o destino não permitiu) que o pesadelo me desmontasse. As lágrimas agora escorrem por minhas faces estragadas. Eu estava na faculdade naquele 18 de setembro em que o exército violou a autonomia e entrou no campus para prender ou matar todo mundo. Não. Na Universidade não houve muitos mortos. Foi em Tlatelolco. Esse nome há de ficar em nossa memória para sempre! Mas eu estava na faculdade quando o exército e os granadeiros entraram e baixaram o cacete na gente. Coisa mais incrível. Eu estava no banheiro, num dos banheiros de um dos andares da faculdade, o quarto, creio, não posso precisar (BOLAÑO, 2008, p. 23).

Assim, percebe-se que o enredo não segue uma linha linear. Presente e futuro se mesclam na descrição de Lacouture, quando ela recorda o momento em que estava escondida no banheiro, no momento em que a UNAM foi invadida em setembro de 1968 e, compara esse acontecimento com o Massacre de Tlatelolco que ocorreu um mês depois. Nessa quebra temporal alucinatória da personagem, o leitor é levado para o passado, presente e futuro sem aviso prévio, que se pode destacar em uma descrição, de um passeio noturno pela capital mexicana, no qual, para Lacouture, a Avenida Guerrero "[...] se parece mais que tudo com um cemitério, mas não com um cemitério de 1974, nem com um cemitério de 1968, nem com um cemitério de 1975, mas com um cemitério do ano de 2666, um 
cemitério escondido debaixo de uma pálpebra morta ou ainda não nascida [...]" (BOLAÑO, 2008, p. 65). Esse trecho já foi analisado por diversos estudiosos da obra de Bolaño, pois, cinco anos depois ele escreveria a sua obra póstuma, o romance clássico 2666. Na análise em construção aqui, levanta-se a hipótese de que esse trecho, na mente perturbada de Lacouture, seria uma metáfora para um futuro violento e sangrento para toda a América Latina. A imagem do cemitério, de um ambiente sombrio e guardião de corpos e memórias dos mortos seriam constantes em diversas temporalidades. Em suma, a América Latina seria um cemitério até o ano de 2666.

Em cada capítulo do enredo literário, Lacouture recorda de suas desventuras e encontros com personagens fictícios e reais. No campo ficcional, têm-se a relação com os poetas León Felipe e Pedro Garfias, e com Elena, noiva de um jornalista italiano, Paolo, que viajaria a Cuba para entrevistar Fidel Castro. No universo real, Lacouture recorda dos seus momentos com Remedios Varo, pintora surrealista hispano-mexicana e de Lilian Serpas, poetisa e jornalista salvadorenha (ALONSO, 2014, p. 85). Outra personagem do campo ficcional merece destaque, trata-se de Arturo Belano.

Arturo Belano foi um alter ego criado por Roberto Bolaño. Estreou no romance Estrela Distante (1996), destacou-se em Detetives Selvagens (1998) e, um ano depois, reapareceu em Amuleto. De acordo com Jáder Vanderlei Muniz de Souza, "São inúmeras as coincidências entre o perfil de Belano e a biografia de Bolaño, entre elas, por exemplo, a idade, os locais de nascimento e residência, a atuação política e literária, além de uma marcante similitude no discurso e na compreensão acerca da literatura e da vida cultural" (SOUZA, 2018, p. 26). Mais do que coincidências, defendo que Belano foi uma proposta literária, no qual, o próprio Bolaño mergulhou em suas narrativas literárias enquanto personagem e expressou os seus sentimentos, desejos, frustrações, medos e esperanças.

Roberto Bolaño seguiu a corrente revolucionária que, no início de 1970, enxergou no Chile de Salvador Allende uma nova proposta emancipatória para a América Latina. Com o objetivo de implantar um Socialismo pelas vias democráticas, o governo de Allende foi sabotado política e economicamente pelas forças conservadoras chilenas, com o apoio dos Estados Unidos. Em 11 de setembro de 1973, o Gen. Augusto Pinochet liderou um Golpe de Estado que sepultou os sonhos revolucionários de Allende. O suicídio de Allende foi o ápice desse violento Golpe de Estado. Após a sua chegada ao poder, o Gen. Pinochet 
implementou o neoliberalismo no Chile e comandou uma das mais sangrentas Ditaduras do Cone Sul latino-americano até a redemocratização, que tornou-se realidade em 1990. Bolaño foi testemunha ocular dessa tragédia chilena e, estando morando no México desde o início da década de 1960, decidiu apoiar o governo de Allende em 1973. Foi preso após o golpe de 11 de setembro, passou algumas semanas encarcerado e foi libertado. Ficou no Chile até o final desse ano e regressou ao México, onde participou de movimentos vanguardistas poéticos e subversivos, antes de se mudar em definitivo para a Espanha e iniciar a sua carreira literária. Essa brevíssima biografia apresentada é essencial na compreensão da relação de Auxilio Lacouture com Arturo Belano.

Em sua narração, a poetisa uruguaia recorda do momento em que conheceu Belano, com dezesseis ou dezessete anos e tornou-se uma grande amiga de sua família. Essa relação foi tão íntima, que Lacouture foi a única pessoa, além dos familiares, que se despediram do alter ego de Roberto Bolaño quando ele regressou ao Chile para fazer a sua parte na proposta revolucionária de Salvador Allende (BOLAÑO, 2008, p. 54). Após o Golpe de Estado de 11 de Setembro, Lacouture participou de manifestações e atos públicos de repúdio ao Governo do Gen. Pinochet:

Encontrei sua irmã e sua mãe [de Belano] na primeira passeata organizada no México depois do golpe. Na época não sabiam nada de Arturo e todas temíamos o pior. Eu me lembro dessa passeata, talvez a primeira que se fez na América Latina por causa da queda de Allende. Nela, vi algumas caras conhecidas de 68 e alguns irredutíveis da faculdade, vi principalmente jovens mexicanos generosos [...] O vale que eu vi, no entanto, não era uma coisinha qualquer. Não sei se era o vale da felicidade ou o vale da desdita. Mas eu o vi, e então vi a mim mesma trancada no banheiro das mulheres e me lembrei que tinha sonhado, quando estava lá, com o mesmo vale e que ao acordar desse sonho ou pesadelo tinha desatado a chorar, ou vai ver que as lágrimas é que me acordaram. Nesse setembro de 1973 aparecia o sonho de setembro de 1968, e isso com certeza queria dizer algo, essas coisas não acontecem por acaso, talvez Arturito já esteja morto, pensei, talvez esse vale solitário seja a figuração do vale da morte, porque a morte é o báculo da América Latina, e a América Latina não pode caminhar sem seu báculo. Mas então a mãe de Arturo me pegou pelo braço (eu estava meio atarantada) e avançamos todas juntas gritando o povo unido jamais será vencido, ai, só de lembrar as lágrimas começam a rolar outra vez (BOLAÑO, 2008, p. 57).

Esse trecho acima é interessante, pois evidencia uma ligação direta entre o ano de 1968 mexicano com o ano de 1973 chileno. Pode-se destacar o relato da personagem do retorno dos mesmos rostos que se levantaram contra o governo do 
México cinco anos atrás e na descrição de que o Chile de Allende poderia ter-se convertido no sonho da juventude insurgente mexicana. Todavia, ao lado dessa descrição, têm-se também o contragolpe da violência que assolou a América Latina nesse período. A imagem de um vale, que em um primeiro momento apareceu para Lacouture como um lugar de paz e felicidade, transformou-se no báculo da morte. A violência que ela presenciou na UNAM, o mar de sangue do Massacre de Tlatelolco de 1968, repetiu-se no pesadelo do Chile de 1973, nas imagens do bombardeio do Palácio de La Moneda, na foto de Allende segurando uma metralhadora com aliados, no registro visual de diversas pessoas mortas, somado com o relato de que o cantor socialista Victor Jara, membro do Partido Comunista Chileno (PCC) foi preso e teve as suas mãos esmagadas quando foi torturado pelo exército comandado pelo Gen. Pinochet. Diante dessas memórias atemporais, o ano violento ano de 1973 passou, a Ditadura do Gen. Augusto Pinochet consolidou-se e Arturo Belano regressou ao México:

Poucos dias depois, em janeiro de 1974, Arturito chegou do Chile e já era outro.

Quero dizer: era o mesmo de sempre, mas no fundo alguma coisa tinha mudado, ou tinha crescido, ou tinha mudado e crescido ao mesmo tempo. Quero dizer: a gente, seus amigos, começou a olhar para ele como se ele fosse outro apesar de ser o mesmo de sempre. Quero dizer: todos esperavam de alguma maneira que ele abrisse a boca e contasse as últimas notícias do Horror, mas ele mantinha sem silêncio, com se o que os demais esperavam houvesse se transformado numa linguagem incompreensível ou não lhe importasse picas (BOLAÑO, 2008, p. 58).

A descrição da mudança sutil de Belano, pelos olhos de Lacouture, no qual ele foi um sobrevivente do horror, com h maiúsculo, demonstra como essa experiência mexeu com Roberto Bolaño, na dificuldade de retorno a normalidade depois de ter vivenciado as atrocidades do Chile do Gen. Pinochet. Na narrativa do romance, após essa experiência, Arturo Belano tornou-se uma pessoa temida e respeitada nos círculos boêmios da Cidade do México, uma vez que ele foi um sobrevivente dessa Ditadura. Outras memórias e desventuras são narradas e, ao fim do romance, Lacouture encerra o seu relato com um canto, uma melodia triste desses tempos, que ao mesmo tempo, poderia sinalizar um espaço de esperança para a América Latina: "E embora o canto que escutei falasse da guerra, das façanhas heróicas (sic) de uma geração inteira de jovens latino-americanos sacrificados, eu soube acima de tudo que falava do destemor e dos espelhos, do desejo e do prazer. E esse canto é nosso amuleto" (BOLAÑO, 2008, p. 131).

Roberto Bolaño vivenciou o México de 1968, o Chile de 1973 e foi testemunha de uma juventude latino-americana sacrificada. Contudo, o que 
poderia ter engendrado a violência nessas duas realidades distantes, que se aproximaram pela trajetória da personagem de Auxilio Lacouture?

Em nossa proposta de resposta, o projeto de uma modernidade capitalista, que esteve nesses dois acontecimentos históricos. No caso do México, o discurso de uma nação moderna, nas trilhas do Primeiro Mundo foi utilizado com bastante veemência na propaganda dos XIX Jogos Olímpicos. Uma possível interferência nessa sintonia discursiva, que poderia ser patrocinada pelos protestos estudantis, deveria e foi anulada, com o já citado Massacre de Tlatelolco e com a perseguição que o governo mexicano efetivou a posterior contra os seus opositores. No caso chileno, o projeto de um Socialismo pelas vias democráticas tornou-se um fenômeno inesperado no embate da Guerra-Fria que, em caso de sucesso, poderia abrir um precedente perigoso para os arautos do oeste capitalista. Atualmente, já se tornou público a interferência do governo dos Estados Unidos na articulação da queda de Salvador Allende. E, é importante frisar, que o governo de exceção do Gen. Augusto Pinochet, trouxe outra experiência inédita para a América Latina: a política neoliberal, no qual o Estado chileno foi pulverizado por políticas econômicas e capitalistas que se tornaram alvo de contestação desde o ano passado. Em ambas as experiências, no qual essa modernidade do capital derrubou governos, vitimou uma geração de jovens e buscou silenciar vozes dissonantes, está a Colonialidade do Poder.

A Colonialidade do Poder só é efetivada com o uso sistemático da violência. Ao conceituar esse processo, Quijano apresentou uma reflexão sobre a dominação dos corpos. Em primeiro lugar, a partir da categorização racial no processo colonial, na dominação corporal foi utilizado pelo sistema escravocrata e religioso diante dos grupos étnicos que povoaram o continente batizado de América. Esse domínio do corpo, em todos os níveis, foi decisivo para o controle e a naturalização da imposição das relações de poder:

[...] Na exploração, é o "corpo" que é usado e consumido no trabalho e, na maior parte do mundo, na pobreza, na fome, na má nutrição, na doença. É o "corpo" o implicado no castigo, na repressão, nas torturas e nos massacres durante as lutas contra os exploradores. Pinochet é um nome do que ocorre aos exploradores no seu "corpo" quando são derrotados nessas lutas. Nas relações de género, trata-se do "corpo". Na "raça", a referência é ao "corpo", a "cor" presume o "corpo" (QUIJANO, 2010, p. 126 - negrito meu).

Destaca-se no trecho acima, a ênfase atribuída a Pinochet na destruição dos corpos em seu governo ditatorial. Quanto mais violento fosse a repressão, mais o 
domínio seria inquestionável, ao utilizar os instrumentos institucionais do terror contra as vozes dissonantes, que por fim, poderiam ser silenciadas. A crueldade e a simbologia dos soldados que esmagaram as mãos de Victor Jara, a pilha invisível dos corpos executados na Praça das Três Culturas de Tlatelolco, e as incontáveis vítimas das Ditaduras latino-americanas, são exemplos do uso da Colonialidade do Poder, que esses governantes, alinhados ao discurso de uma modernidade capitalista, não se furtaram de impor aos seus adversários. No romance de Roberto Bolaño, a Colonialidade do Poder está presente nas memórias atemporais de Auxilio de Lacouture, na mudança sofrida por Arturo Belano após a sua experiência no Chile e na descrição de que a América Latina seria um vale da morte e a violência, o seu báculo de sustentação que golpeou uma geração juvenil. Todavia, Amuleto também pode ter outra chave de leitura. De acordo com Luciano Alonso:

Amuleto también puede entenderse como una novela policial: el crimen que se ha cometido es contra toda una generación, a la que le quitaron los sueños, la posibilidad de construir un mundo mejor. Los jóvenes que soñaron con la revolución serían las víctimas. El Golpe de Estado y las represiones militares serían los victimarios. El lector sería el detective. Y el veredicto aún no ha sido formulado (ALONSO, 2014, p. 89).

Concomitantemente, Amuleto pode ser interpretada como uma narrativa de denúncia e de posicionamento político, no qual, a partir do campo cultural e literário, a Colonialidade do Poder foi exposta e enfrentada.

\section{CONSIDERAÇÕES parciais}

Apesar da força dominadora da Colonialidade do Poder, não podemos deixar de lado as resistências e rupturas. Quijano não foi um pessimista em suas análises, mesmo pontuando as derrotas dos projetos revolucionários da América Latina e de todo o globo, seria possível a emancipação dessa Colonialidade, desde que iniciássemos uma mudança de perspectiva em que poderíamos tirar a América Latina do concepção ser apenas um imenso projeto ou laboratório de dominação da modernidade capitalista: "Conseqüentemente (sic), é tempo de aprendermos a nos libertar do espelho eurocêntrico onde nossa imagem é sempre, necessariamente, distorcida. É tempo, enfim, de deixar de ser o que não somos" (QUIJANO, 2005, p. 274). 
O próprio romance de Roberto Bolaño apresenta um lado de contestação e de resistências nas entrelinhas. Auxilio de Lacouture foi inspirada em uma personagem real, Alcira Soust Scaffo (ALONSO, 2014, p. 87). Professora e poeta uruguaia, Scaffo ficou escondida por 15 dias em um banheiro no oitavo piso da Torre de Humanidades da UNAM, quando a Universidade foi invadida por militares em setembro de 1968. Ou seja, a história narrada em Amuleto foi a partir de um caso verdadeiro, de uma resistência, de uma voz dissonante, em que o corpo de Scaffo/Lacouture não cedeu diante da repressão da Colonialidade do Poder dos mandatários mexicanos.

A personagem de Arturo Belano é outro exemplo da resistência desse período, nesse caso, na imagem do seu próprio criador, Roberto Bolaño, que foi um sobrevivente dos anos de chumbo. Diante disso, a produção literária de Bolaño pode ser interpretada como uma grande denúncia de toda a violência que a América Latina foi e ainda é vitimada. Ao destacar a violência das Ditaduras militares, da violência de gênero, do feminicídio, a partir da exposição da crueldade humana, Bolaño deixou nus os agressores e expôs as contradições do ser humano. A partir da caída dessas máscaras, a resistência a essas realidades podem ser aglutinadas e, finalmente, tornarem-se vozes de discórdia e de rupturas de um passado que não deve retornar. Os movimentos atuais contra políticas conservadoras, contra discursos de ódio, contra a violência de gênero, entre outros, é uma prova de que a Colonialidade do Poder sempre encontrará resistência.

Quiçá, essas perseveranças possam tornar realidade uma América Latina que seja um vale da felicidade, igual a imagem que a personagem de Auxilio Lacouture visualizou em 1973, quando, em solo mexicano, levantou-se contra o Golpe de Estado chileno de 1973, contra a repressão de 1968 e, contra todas as violências, tanto do passado quanto do futuro.

\section{REFERÊNCIAS}

ALONSO, Luciano. Roberto Bolaño: una guía de lectura. Argentina: Milena Caserola, 2014.

ANDREWS, George Reid. América Afro-Latina, 1800-2000. São Carlos: EdUFSCAR, 2007. 
BOLAÑO, Roberto. Amuleto. São Paulo: Companhia das Letras, 2008.

CASTILLO TRONCOSO, Alberto del. Ensayo sobre el movimiento estudiantil de 1968: la fotografía y la construcción de un imaginario. México: Instituto Mora: IISUE, 2012.

QUIJANO, Anibal. "Colonialidade do poder, Eurocentrismo e América Latina". In: LANDER, Edgard (Org.). A colonialidade do saber: eurocentrismo e ciências sociais. $1^{\mathrm{a}}$ ed. Buenos Aires: Consejo Latioamericano de Ciencias Sociales - CLACSO, 2005, p. 227-278.

. "Colonialidade do poder e classificação social". In: SANTOS, Boaventura de Sousa \& MENESES, Maria Paula (Orgs.). Epistemologias do Sul. São Paulo: Cortez, 2010, p. 84-130.

SANTOS, Clara Bomfim dos. Narrativas da violência: Estrella Distante, Amuleto e Nocturno de Chile de Roberto Bolaño. Dissertação (mestrado em Literatura do Departamento de Teoria Literária e Literaturas - TEL do Instituto de Letras da Universidade de Brasília - UNB). Brasília-DF: Universidade de Brasília/UNB, 2015.

SMITH, Peter H. "México, 1946-c.1990". In: BETHELL, Leslie (Org.). A América Latina após 1930: México, América Central, Caribe e Repúblicas Andinas (História da América Latina - Volume IX). São Paulo: Editora da Universidade de São Paulo, 2015, p. 111-192.

RODRÍGUEZ ALMONACID, Carmen Cecilia. História, memória e violência em Nocturno de Chile, Estrella distante e Amuleto de Roberto Bolaño. Dissertação (mestrado em Teoria e História Literária na área de História e Historiografia Literária). Campinas: Universidade Estadual de Campinas/UNICAMP, 2012.

SOUZA, Jáder Vanderlei Muniz de. Roberto Bolaño e a utopia de Arturo Belano. Tese (doutorado em Letras). São Paulo: Universidade de São Paulo/USP, 2018.

Artigo recebido em: 30 de setembro de 2020 . Artigo Aprovado em: 16 de dezembro de 2020. 